\title{
Genotyping-by-sequencing based genetic mapping reveals large number of epistatic interactions for stem rot resistance in groundnut
}

\author{
Sneha M. Dodia ${ }^{1}$ Binal Joshi ${ }^{1} \cdot$ Sunil S. Gangurde ${ }^{2}$ (]) $\cdot$ Polavakkalipalayam P. Thirumalaisamy ${ }^{1}$.

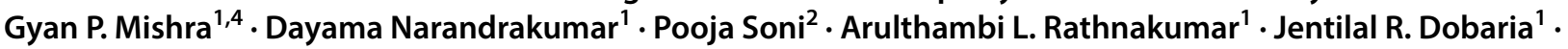 \\ Chandramohan Sangh ${ }^{1} \cdot$ Annapurna Chitikineni ${ }^{2} \cdot$ Sumitra V. Chanda ${ }^{3} \cdot$ Manish K. Pandey $^{2}{ }^{\circledR}$. \\ Rajeev K. Varshney ${ }^{2}$ (D) Radhakrishnan Thankappan ${ }^{1}[$
}

Received: 21 May 2018 / Accepted: 30 November 2018

c) Springer-Verlag GmbH Germany, part of Springer Nature 2018

\begin{abstract}
Key message Genetic mapping identified large number of epistatic interactions indicating the complex genetic architecture for stem rot disease resistance.

Abstract Groundnut (Arachis hypogaea) is an important global crop commodity and serves as a major source of cooking oil, diverse confectionery preparations and livestock feed. Stem rot disease caused by Sclerotium rolfsii is the most devastating disease of groundnut and can cause up to $100 \%$ yield loss. Genomic-assisted breeding (GAB) has potential for accelerated development of stem rot resistance varieties in short period with more precision. In this context, linkage analysis and quantitative trait locus (QTL) mapping for resistance to stem rot disease was performed in a bi-parental recombinant inbred line population developed from TG37A (susceptible) $\times$ NRCG-CS85 (resistant) comprising of 270 individuals. Genotyping-bysequencing approach was deployed to generate single nucleotide polymorphism (SNP) genotyping data leading to development of a genetic map with 585 SNP loci spanning map distance of $2430 \mathrm{cM}$. QTL analysis using multi-season phenotyping and genotyping data could not detect any major main-effect QTL but identified 44 major epistatic QTLs with phenotypic variation explained ranging from 14.32 to $67.95 \%$. Large number interactions indicate the complexity of genetic architecture of resistance to stem rot disease. A QTL of physical map length 5.2 Mb identified on B04 comprising 170 different genes especially leucine reach repeats, zinc finger motifs and ethyleneresponsivefactors, etc., was identified. The identified genomic regions and candidate genes will further validate and facilitate marker development to deploy GAB for developing stem rot disease resistance groundnut varieties.
\end{abstract}

Communicated by Henry T. Nguyen.

Electronic supplementary material The online version of this article (https://doi.org/10.1007/s00122-018-3255-7) contains supplementary material, which is available to authorized users.

Rajeev K. Varshney

r.k.varshney@ cgiar.org

Radhakrishnan Thankappan

radhakrishnan.nrcg@gmail.com

1 ICAR-Directorate of Groundnut Research (ICAR-DGR), Junagadh 362001, India

2 International Crops Research Institute for the Semi-Arid Tropics (ICRISAT), Hyderabad 502324, India

3 Saurashtra University, Rajkot 360 005, India

4 Indian Agricultural Research Institute (IARI), New Delhi 110012, India

\section{Introduction}

Groundnut, also known as peanut (Arachis hypogaea L.), is an important global crop commodity and serves as a major source of cooking oil, diverse confectionery preparations and livestock feed. Stem rot caused by Sclerotium rolfsii, a necrotrophic soilborne fungus, is most serious among biotic stress of groundnut, which commonly occurs in the tropics, subtropics and other warm temperate regions of the world (Deepthi and Reddy 2013). The disease occurs in almost all the groundnut-producing areas with yield loss commonly ranging from 10 to $40 \%$ but can reach over $80 \%$ in heavily infested fields (Akgul et al. 2011; Bera et al. 2014). The pathogen ( $S$. rolfsii) mainly infects the stems, but it also attacks leaves, pods and all parts of the plant, therefore causing severe damage during all stages of crop growth (Cilliers et al. 2000; Ganesan et al. 2007). Although several 
strategies, such as cultural methods and use of chemicals and fungicides, can be employed to control this disease, these methods cannot be used effectively due to late diagnosis of disease. Further, the above strategies bring extra financial burden on farmers in addition to damaging the ecosystem. Such situation can be dealt by developing stem rot resistant varieties using reliable host-plant resistance and cultivation in farmers' field. In order to ensure timely replacement of improved varieties with enhanced resistance to stem rot, GAB has the potential to facilitate accelerated development of improved varieties with more precision (Varshney et al. 2009; Pandey et al. 2012; Varshney et al. 2013).

In order to deploy GAB, tightly linked markers are required for precise selection of breeding lines. Among all the trait mapping approaches, sequencing-based genetic mapping would be the most suitable method for performing high-resolution mapping for candidate gene discovery and marker development (Pandey et al. 2016). We can generate thousands of data points for conducting high-resolution trait mapping using next-generation sequencing technologies such as genotyping-by-sequencing (GBS), whole-genome resequencing (WGRS) or SNP array-based genotyping (Pandey et al. 2017). Most recently, a sequencing-based trait mapping approach, QTL-Seq, has been successfully deployed for detection of genomic regions, candidate gene discovery and marker development for foliar disease resistance (Pandey et al. 2017). Considering the cost-effectiveness, GBS seems to have comparative advantages over other sequencing-based methodologies. Nevertheless, several mapping efforts were successfully deployed in past using different genotyping methods including GBS leading to identification of genomic regions and linked markers for several agronomic, quality and disease resistance traits (Vishwakarma et al. 2017).

Molecular breeding has already demonstrated its strength in accelerated improvement of target traits in groundnut including disease resistance traits (Varshney et al. 2014). Now, reference genome for cultivated tetraploid (https:// peanutbase.org/node/587309) has also become available in addition to earlier available genome assemblies of diploid progenitors (Bertioli et al. 2016; Chen et al. 2016). The availability of tetraploid genome assembly will further enhance the precision of sequence analysis, annotation, candidate gene discovery and marker development. Further, recombinant inbred line (RIL) population provides better option for generating replicated and multi-season phenotyping data in different locations to decipher the environmental effect on target traits. Such phenotyping data are must for detection of stable and consistent QTLs followed by detection of linked markers for use in breeding. Considering above facts, this study reports development and use of a RIL population for generating GBS-based genotyping data and multi-environment phenotyping data for resistance to stem rot disease. The results of this study helped in developing better trait understanding and mapping leading to successful identification of genomic regions controlling stem rot resistance.

\section{Materials and methods}

\section{Plant materials and development of RIL population for stem rot disease}

A recombinant inbred line (RIL) population was developed using TG37A (stem rot susceptible) $\times$ NRCG CS85 (stem rot resistant) comprising of 270 individuals (RILs) at ICARDirectorate of Groundnut Research (DGR), Junagadh, India (Fig. 1). The resistant parent, NRCG CS85, had pedigree of $(\mathrm{CT} 7-1 \times \mathrm{SB} 11) \times A$. kretschmeri with growth habit type-Virginia bunch and resistant to multiple diseases, viz. PBND, stem rot, late leaf spot, rust and Alternaria leaf blight (Bera et al. 2011). This parent was selected and used as the resistant donor based on its stable resistance for stem rot disease over the years and locations (Bera et al. 2011). On the other hand, the female parent, TG37A (TG $25 \times$ TG 26), with botanical type Vulgaris and growth habit type Spanish bunch, is high yielding, moderately tolerant to collar rot, rust and LLS, and drought tolerant and possess fresh seed dormancy up to 15 days (Kale et al. 2004).

The hybridization was performed in net house at ICARDirectorate of Groundnut Research (DGR), Junagadh, India, in the rainy season of 2013 . The pots $(30 \mathrm{~cm}$ diameter and $35 \mathrm{~cm}$ height) containing mixture of dry soil, fine sand and well-decomposed farmyard manure (3:1:1 proportion) were kept on raised platforms. One seed per pot was sown, and a total of 15 plants for female parent while 10 plants for male parent were raised. Emasculation and pollination were performed as described by Nigam et al. (1990) with minor modifications. The single seed of putative hybrids $\left(\mathrm{F}_{1} \mathrm{~s}\right)$ obtained through crossing were grown in cups filled with fine sand and screened with polymorphic SSR primers detected between parents. The identified hybrid plants were transferred to earthen pots, and the confirmed $F_{1}$ s were advanced to $\mathrm{F}_{2} \mathrm{~s}$ by selfing. The single seed descent (SSD) method under field conditions was used till $\mathrm{F}_{6}$ generation for developing RIL population (Fig. 1).

\section{Phenotyping for stem rot resistance and yield traits}

For phenotyping, a total of 270 RILs ( $\mathrm{F}_{6}$ generation) were planted in 3 replications along with their parents in earthen pots under controlled P-II glasshouse conditions in three seasons [rainy 2016 (S1), post-rainy 2017(S2) and rainy 2017(S3)] (Fig. 1). The plant height was measured in centimetres $(\mathrm{cm})$ from the ground level to the tip of the main 
(a)

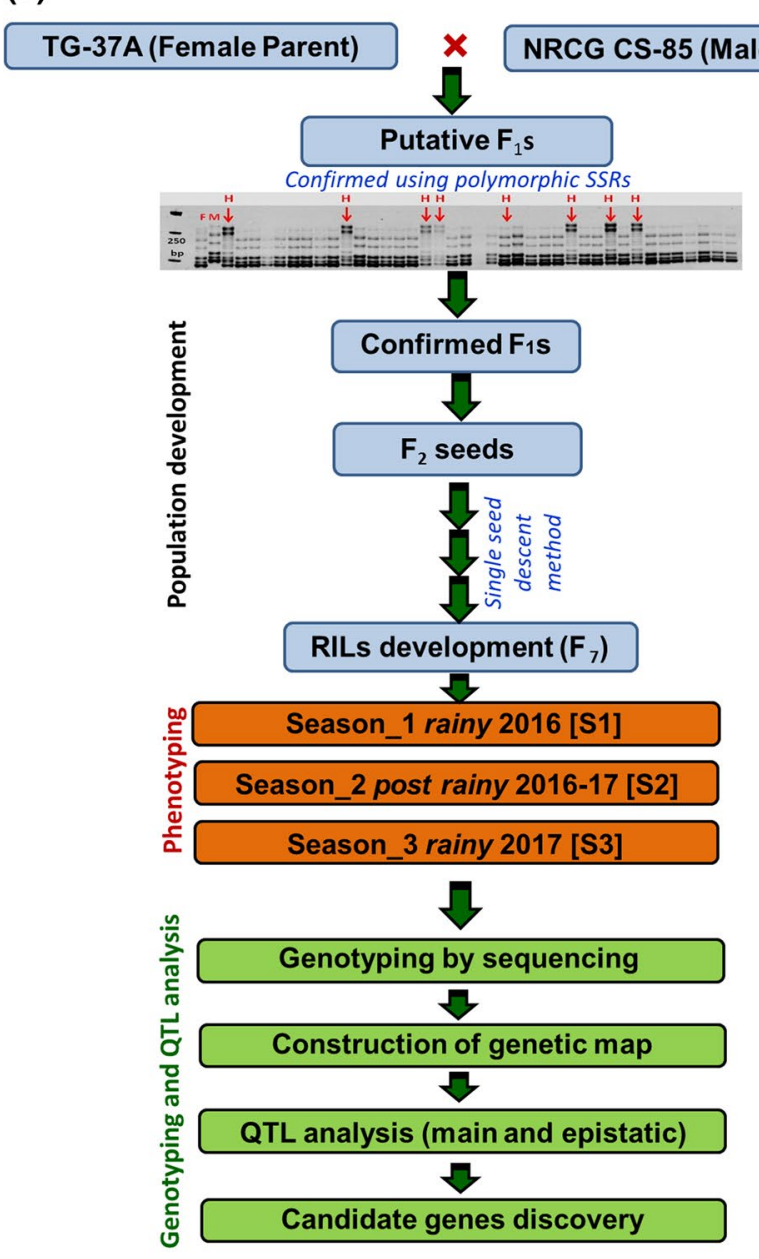

(c)

(b)
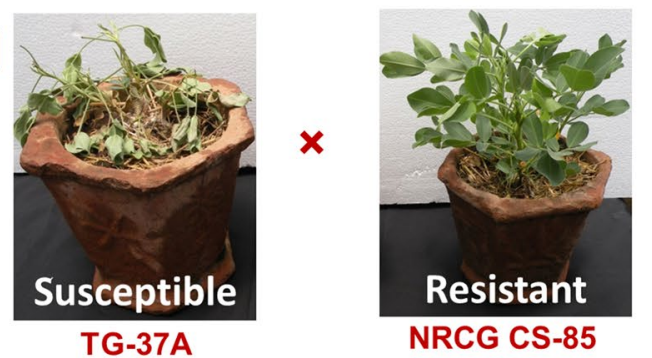

(d)

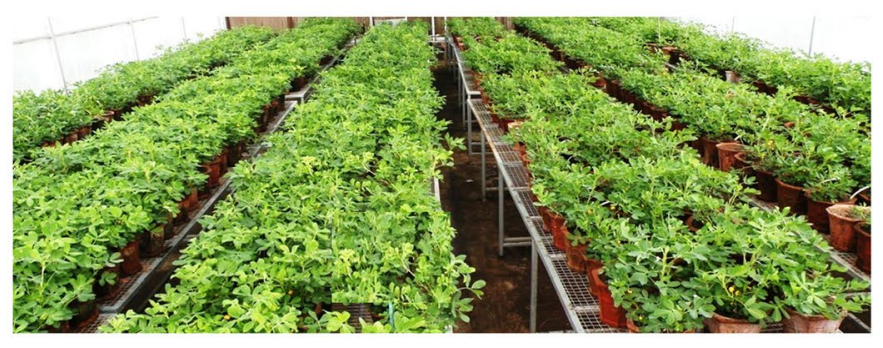

\section{Disease score on the basis of mortality \%}

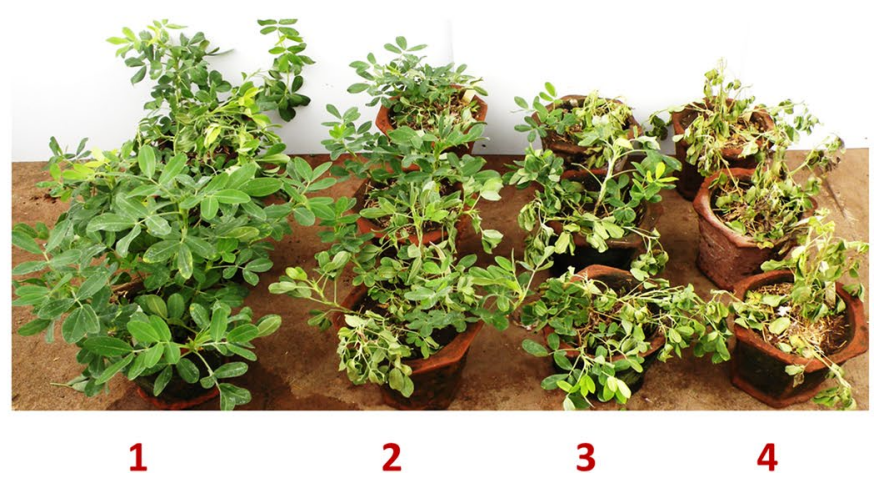

Fig. 1 Flow chart for population development, high-density genotyping and multi-season phenotyping. a Development of RIL population following SSD method followed by phenotyping and genotyping; $\mathbf{b}$ Susceptible (TG 37-A) and resistant (NRCG CS-85) parents used

for developing RIL population; c 70-days-old plants used for the infection with Sclerotium rolfsii spores; and d Mortality percentage recorded at 6DAI, 9DAI and 12DAI after infection

stem after 60 days of sowing. Number of primary branches and total number of secondary branches were recorded after 60 days of sowing. Stem surface of each RIL was observed after 60 days of sowing for presence of hairs on the stems lines and was scored as 0: glabrous; 1: pubescent (sparse); 2: pubescent (dense). Shape of fully expanded apical leaflet of the third leaf of the main stem was observed and scored as 1: ovate and 2: lanceolate. Length of ten mature pods and seeds from each RIL was measured in $\mathrm{mm}$ after harvesting. Shelling percentage was calculated for each RIL as kernel weight/pod weight and expressed in percentage.

For disease screening, 70-days-old plants were infected with $S$. rolfsii. To do so, wheat straw was spread to the soil surface of the pots and each plant was infected by applying the $S$. rolfsii which was multiplied on autoclaved sorghum grains for 15 days at $2 \mathrm{~g}$ per plant around the base of the main stem. Wilting (\%) of plants was recorded at regular interval of 3 days. First observation was recorded at 6 days after inoculation (6 DAI), second at 9 days after inoculation (9 DAI) and third at 12 days after inoculation (12 DAI) in season S1, S2 and S3. Disease intensity was measured using 1-4 scale (modified scale of Shokes et al. 1998) as described in Table 1.

\section{DNA extraction and sequencing}

DNA from 270 RILs and the two parents was extracted using NucleoSpin Plant II kit (Macherey-Nagel, Duren, Germany). The DNA quality and quantity were checked on $0.8 \%$ agarose and then Qubit 2.0 fluorometer (Thermo Fisher Scientific Inc., USA). Genotyping-by-sequencing (GBS) (Elshire et al. 2011) was performed for entire RIL 
Table 1 Scoring of disease reaction, disease intensity and rating scale used (modified from the 1 to 5 scale of Shokes et al. 1998)

\begin{tabular}{llll}
\hline S. No. & Disease reaction & Disease intensity & Rating scale \\
\hline 1 & R: Resistant & $<10 \%$ drying of plant & 1 \\
2 & MR: Moderately resistant & 10 to 25\% drying of plant & 2 \\
3 & MS: Moderately susceptible & $>25$ to 50\% drying of plant & 3 \\
4 & S: Susceptible & $>50 \%$ drying of plant & 4 \\
\hline
\end{tabular}

population for simultaneous SNP discovery and genotyping of mapping population. To do so, $10 \mathrm{ng}$ DNA from each RIL was digested using the restriction enzyme ApeKI endonuclease which recognizes the site: G/CWCG. The ligation enzyme, T4 ligase, was used to ligate the digested products with uniquely barcoded adapters. Such digestion and ligation were performed for each RIL, and then, equal proportion from each sample was mixed to construct the libraries. These libraries were then amplified and purified to remove excess adapters. These DNA libraries were then sequenced on HiSeq 2500 platform (Illumina Inc, San Diego, CA, USA) to generate genome-wide sequence reads.

\section{Sequence analysis and SNP calling}

The sequence raw reads in the form of FASTQ files generated for RIL population and parental genotypes were used for SNP discovery using TASSEL v4.0 (Bradbury et al. 2007). The draft genome sequences of groundnut progenitors, namely A. ipaensis and A. duranensis, were used as reference assembly for SNP calling (Bertioli et al. 2016; Chen et al. 2016). Initially, the in-house script was used to detect perfectly matched barcode with four base remnant of the digestion site of the restriction enzyme in sequencing reads generated for RIL and parental genotypes. The above information on barcoding was then used for sorting and demultiplexing the sequence reads. These reads were then used for trimming up to first 64 bases starting from the cut site of the restriction enzyme. In order to filter quality sequencing data, the reads containing ' $N$ ' within first 64 bases were identified and discarded from further analysis. Finally, those reads containing ' $N$ ' within first 64 bases were rejected. The sequence reads which passed above quality filtering criteria (called as tags) were aligned against draft genome sequence of groundnut progenitors using Burrows-Wheeler Alignment (BWA) tool (Li and Durbin 2009). The alignment file was then processed for SNP calling and genotyping. The individuals with less than $80 \mathrm{Mb}$ data were not selected for further analysis to avoid false-positive detection. Lines with more than 50\% missing data and minor allele frequency (MAF) of $\leq 0.3$ were filtered out. Further, imputation of missing data was carried out using FSFHap algorithm implemented in TASSEL v4.0 in the mapping populations. The imputed SNPs were again filtered with MAF cut-off of 0.2 to remove missing data, and such filtered SNPs were used for genetic mapping and QTL studies.

\section{Phenotypic data analysis}

Phenotyping data were analysed using software Genstat 15th edition. Association among different stem rot disease-related traits and yield-related traits was established using Pearson correlation and calculating a two-tailed $p$ value with $95 \%$ confidence intervals. Skewness, kurtosis, standard deviation, $p(\mathrm{~W}) p$ values corresponding to Shapiro-Wilk test for normality and coefficient of variation were also calculated using ICIM mapping software version 4.0 (Wang et al. 2012).

\section{Construction of genetic linkage map}

The chi-square $\left(\chi^{2}\right)$ values calculated for each SNP marker were used to determine the goodness of fit to the expected 1:1 segregation ratio; highly distorted and unlinked markers were filtered out and not considered for the linkage map construction. Allelic calls in the population based on the parents were assigned the numeric values of $-1,0$ or 2 as specified in the manual. The genetic map was constructed using JoinMap version 4 (Van Ooijen 2006). The grouping and ordering of markers were carried out using regression mapping algorithm. Kosambi's mapping function was used for converting the recombination frequency into map distance in centiMorgan (cM). Markers at the same locus (with $0 \mathrm{cM}$ interval) were counted with zero recombination frequency. The markers were ordered in 20 linkage groups by applying the LOD score (logarithm of the odds) with LOD threshold ranging from 3 to 10 with minimum recombination frequency threshold $(\partial)$ of $50 \%$. For better visualization and clarity, software called MapChart was used to draw final genetic map (Voorrips 2002).

\section{Quantitative trait loci (QTLs) analysis}

Composite interval mapping (CIM) using the software QTL cartographer (Wang et al. 2011) was performed using the genotyping and phenotyping data together with genetic map information. In addition, the above information was also used to perform inclusive composite interval mapping-additive (ICIM-ADD) analysis using the ICIM software (Meng et al. 2015). In ICIM, the $p$ values for entering variables 
(PIN) and removing variables (POUT) were set at 0.001 and 0.002 , and the scanning step was $1.0 \mathrm{cM}$. LOD threshold value of 3.0 was used to declare the presence of a QTL. A QTL was considered to be major only if had a LOD of $\geq 3$ and PVE explained $>10 \%$; the rest were considered as minor QTLs. The QTLs were designated with initial letter 'q' followed by the trait name and chromosome number. If there were more than one QTL for a trait, then it was suffixed by the numeric values as _1,_2 and so on.

\section{Identification of epistatic $(Q \times Q)$ and environment effect $(Q \times E)$ QTLs}

Realizing the complexity of stem rot resistance, we identified $Q \times Q$ interactions (epistatic QTLs) for disease resistance to detect combined effect of two or more genomic regions (QTLs) on the stem rot disease. The genetic map information together with phenotyping data was used for identification of epistatic QTLs for stem rot using ICIM mapping software version 4.0 (Wang et al. 2012). Inclusive composite interval mapping (ICIM) for epistatic QTLs with additive (two-dimensional scanning, ICIM-EPI) method with $5 \mathrm{cM}$ step and 0.001 probability mapping parameters in stepwise regression were employed in QTL analysis. The LOD threshold score of 3.0 was used as minimum significance level for epistatic QTLs.

\section{Results}

\section{Phenotypic variation for disease resistance and yield-related traits in RIL population}

Replicated and multi-season phenotyping data generated in rainy 2016 (S1), post-rainy 2017 (S2) and rainy 2017 (S3) for stem rot disease in RIL population showed good variation with highest PCV \% of 74.0 (6 DAI) followed by $36.0 \%$ (9 DAI), and $22.3 \%$ (12 DAI) while highest GCV \% of $42.1 \%$ (6 DAI) followed by $14.9 \%$ (9 DAI), $10.7 \%$ (12 DAI). The level of resistance was ranging from 0 to $100 \%$ damage across infection stages (6 DAI, 9 DAI and 12 DAI) and seasons. The parental genotypes 'NRCG CS85' showed resistance to stem rot disease with just $0-10 \%$ percentage of infection while 'TG37A' showed susceptibility with $50-100 \%$ percentage of infection. Disease scoring of stem rot disease followed normal distribution at 6 DAI. But due to high disease pressure during $9 \mathrm{DAI}$ and $12 \mathrm{DAI}$, the curve was quite skewed due to high disease pressure across three seasons (S1, S2 and S3) and three treatments (6 DAI, 9 DAI and 12 DAI) (Fig. 2). All the three observations provided a clear understanding about the infection percentage, which increased with increasing time; i.e., curve is getting skewed with increasing time of infection. At primary stage of infection (6 DAI, 9 DAI), the disease did not show significant correlation with yield-related traits. However, stem rot disease showed significant negative correlation with pod length and seed length at advanced stage of infection (12 DAI) (Table 2).

\section{Genotyping-by-sequencing, SNP discovery and genetic mapping}

GBS approach was used to generate a total of $30.02 \mathrm{~Gb}$ (297.77 million reads) clean reads using HiSeq 2500 platform for 270 RILs segregating for stem rot disease and the parental genotypes. The reads from individual progenies ranged from 0.80 to 4.79 million reads across RIL population. A total of 1.14 million SNPs were detected across RIL population, and 36,429 SNPs were found polymorphic between the parents. Out of these polymorphic SNPs, 9115 SNPs were filtered out having MAF) of 0.3 and less than $30 \%$ missing data. These polymorphic SNPs were nonuniformly distributed across different pseudomolecules. Of the 9115 SNPs (average read depth of 70.7), further filtering based on per cent heterozygosity and polymorphic information identified 735 high-quality polymorphic SNPs for further genetic analysis. Stringent SNP selection criteria reduced number of SNPs from several millions to few hundreds.

The imputed 735 polymorphic SNPs from RIL population were used for construction of genetic map. Finally, a genetic map with 585 SNP loci was developed with a total map distance of $2430 \mathrm{cM}$. The remaining unmapped 250 loci either were highly distorted or had more missing data. The length of individual linkage groups varied from $4.9 \mathrm{cM}$ (A02) to $262.5 \mathrm{cM}$ (A03). Total 266 loci were mapped in A sub-genome with total map distance $1092 \mathrm{cM}$, whereas 319 loci were mapped in B sub-genome with total map distance $1337.8 \mathrm{cM}$. A maximum number of loci mapped in individual linkage group varied from 3 (A02) to 62 (B10). The average inter-marker distance per linkage group ranged from $1.5 \mathrm{cM}$ (A10) to $16.1 \mathrm{cM}$ (B01). The average map density was high $(0.66$ loci/cM) for the linkage group A10 and minimum (0.061 loci/cM) for B01 (Table 3).

\section{Genomic regions controlling plant architecture and stem rot resistance identified using QTL Cartographer and ICIM}

QTL analysis was performed using two different methods composite interval mapping (CIM) using software QTL cartographer and inclusive composite interval mapping additive (ICIM-ADD) using the software ICIM. In total, 20 main-effect QTLs (M-QTLs) were identified for various plant architecture- and disease-related traits using QTL cartographer and ICIM with LOD score ranging 


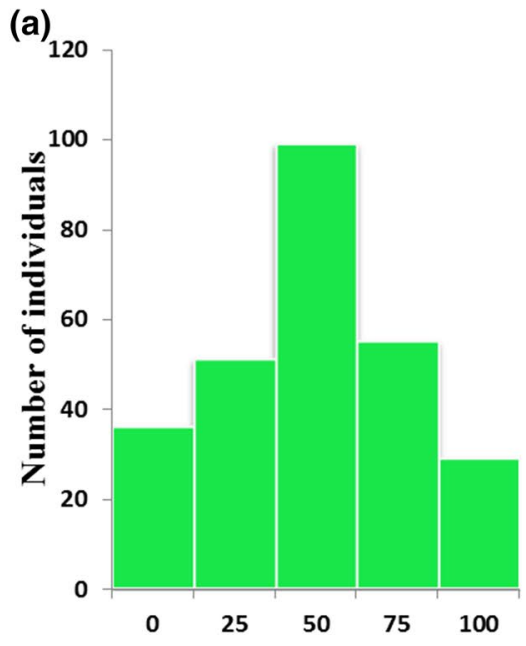

6 Days after infection_S1

(d)

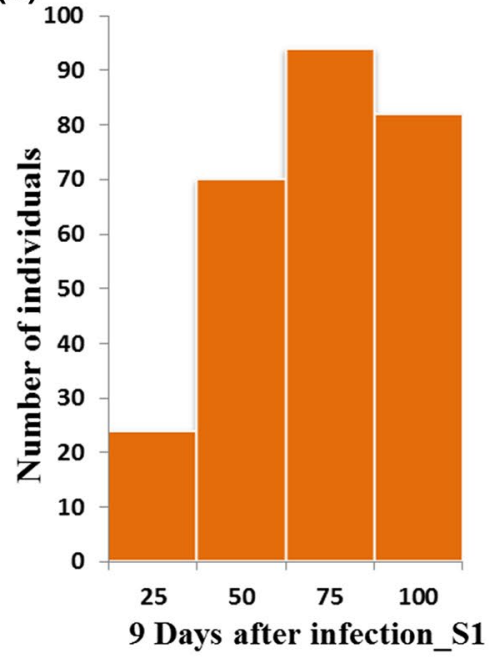

(g)

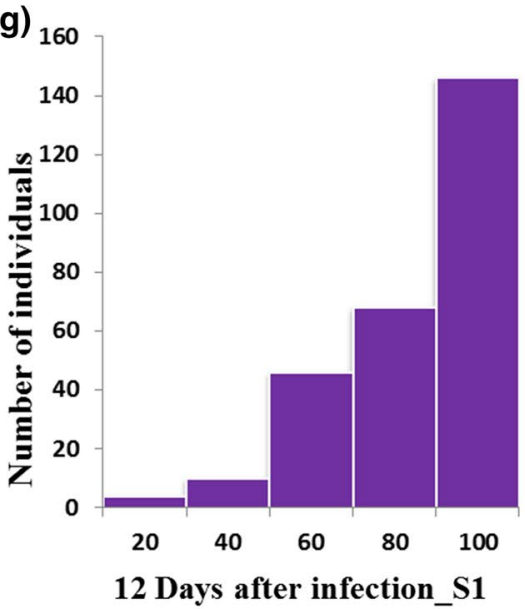

(b)

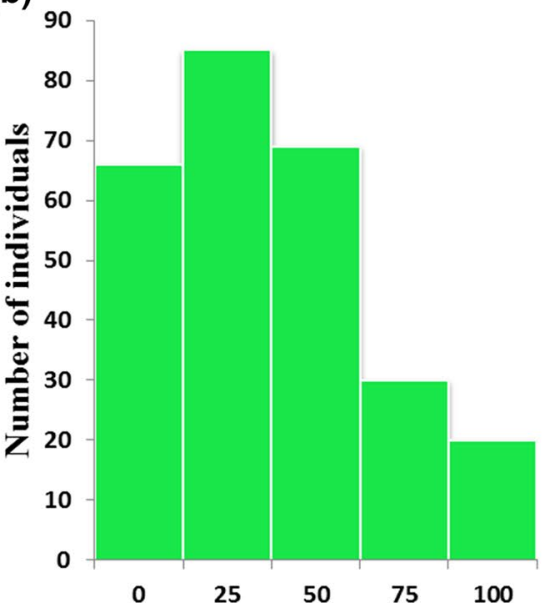

6 Days after infection_S2

(e)

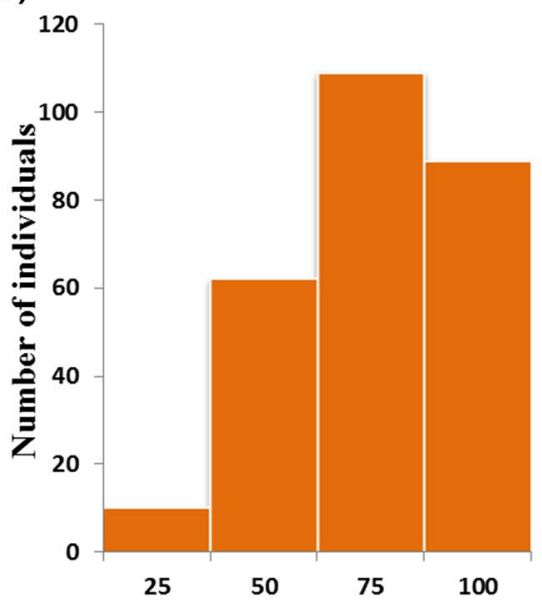

9 Days after infection_S2

(h)

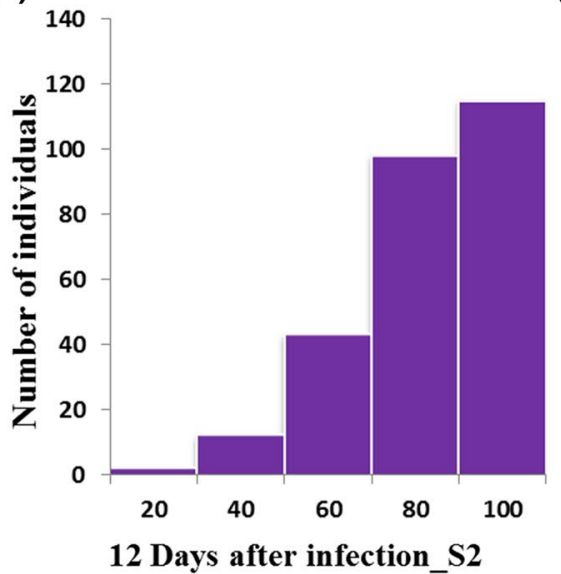

(c)

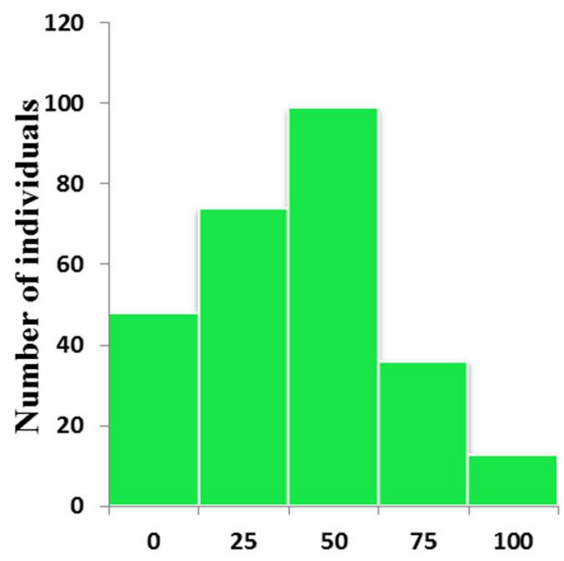

6 Days after infection_S3

(f)

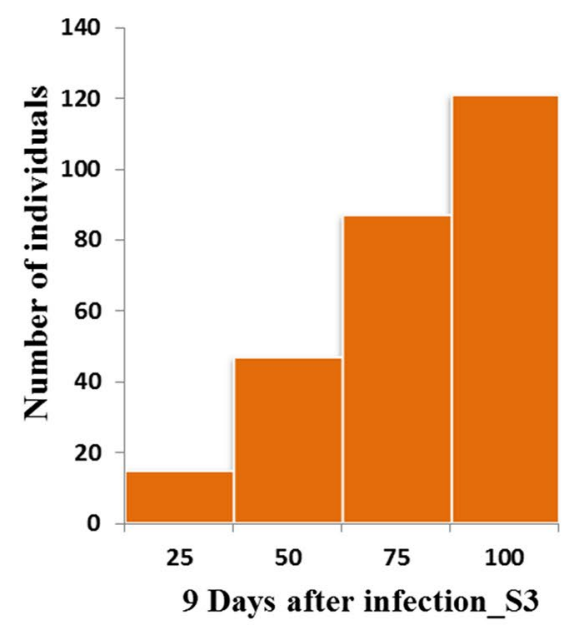

(i) 200

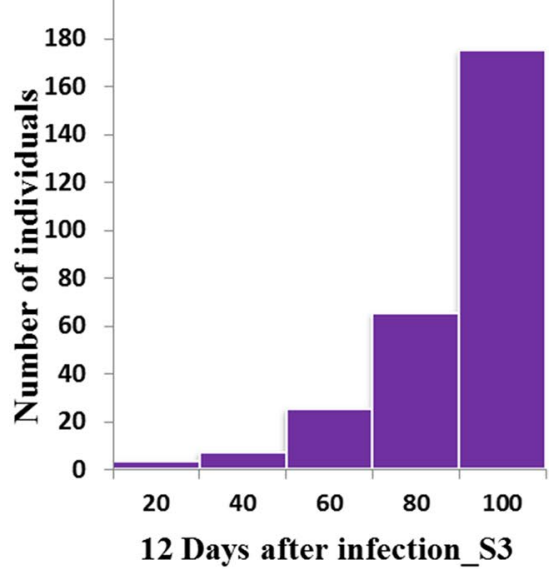

Fig. 2 Frequency distribution for stem rot disease resistance at different infection stages. The $x$-axis shows the percentage of disease, and the $y$-axis represents the number of individuals in the $\mathrm{F}_{8}$ population.
Seasons are denoted as (S1)-rainy 2016, (S2)-post-rainy 2017 and (S3)-rainy 2017 
Table 2 Pearson correlation between disease and yieldrelated traits

\begin{tabular}{llllllrrr}
\hline Variables & PH & LL & LW & SP & PL & PW & \multicolumn{1}{l}{ SL } & \multicolumn{1}{l}{ SW } \\
\hline 6 DAI & 0.11 & -0.06 & -0.03 & 0.02 & -0.05 & -0.06 & -0.06 & -0.04 \\
9 DAI & 0.09 & -0.03 & -0.07 & 0.06 & 0.02 & 0.01 & 0.03 & 0.05 \\
12 DAI & 0.03 & -0.04 & -0.02 & -0.09 & $-0.16^{* *}$ & 0.00 & $-0.18^{* *}$ & -0.01 \\
\hline
\end{tabular}

$P H$ plant height, $L L$ leaf length, $L W$ leaf width, $S P$ shelling percentage, $P L$ pod length, $P W$ pod weight, $S L$ seed length, $S W$ seed weight, 6 DAI 6 days after infection, 9 DAI 9 days after infection, 12 DAI 12 days after infection

$*$,**Statistically significant at $1 \%$ and $5 \%$ level of significance respectively

Table 3 Features of the saturated genetic map with 585 mapped loci for TG37-A x NRCG CS-85

\begin{tabular}{|c|c|c|c|c|c|c|c|}
\hline Linkage group & Mapped loci & $\begin{array}{l}\text { Length of LG } \\
\text { (cM) }\end{array}$ & $\begin{array}{l}\text { Map density } \\
\text { (cM/loci) }\end{array}$ & Linkage group & Mapped loci & $\begin{array}{l}\text { Length of LG } \\
\text { (cM) }\end{array}$ & $\begin{array}{l}\text { Map density } \\
\text { (cM/loci) }\end{array}$ \\
\hline A sub-genome & & & & B sub-genome & & & \\
\hline A01 & 52 & 221.8 & 4.3 & B01 & 10 & 161.4 & 16.1 \\
\hline A02 & 3 & 4.9 & 1.6 & B02 & 34 & 90.9 & 2.7 \\
\hline A03 & 35 & 262.5 & 7.5 & B03 & 34 & 200.8 & 5.9 \\
\hline A04 & 19 & 46.8 & 2.5 & B04 & 38 & 106.3 & 2.8 \\
\hline A05 & 30 & 97.0 & 3.2 & B05 & 15 & 135.9 & 9.1 \\
\hline A06 & 17 & 67.2 & 4.0 & B06 & 43 & 92.3 & 2.1 \\
\hline A07 & 12 & 94.8 & 7.9 & B07 & 59 & 230.7 & 3.9 \\
\hline A08 & 7 & 33.0 & 4.7 & B08 & 13 & 43.0 & 3.3 \\
\hline A09 & 50 & 202.0 & 3.4 & B09 & 11 & 173.4 & 15.8 \\
\hline A10 & 41 & 62.5 & 1.5 & B10 & 62 & 103.0 & 1.7 \\
\hline Total & 266 & 1092.5 & 4.11 & & 319 & 1337.8 & 4.2 \\
\hline Grand total & 585 & 2430 & 4.15 & & & & \\
\hline
\end{tabular}

from 3.2 to 12.2 and phenotypic variance explained (PVE $\%$ ) ranging from 4.91 to $10.34 \%$ (Table 4; Fig. 3).

\section{QTLs for stem rot resistance}

Seven main-effect QTLs were identified for stem rot resistance with LOD score ranging from 3.1 to 5.4 and PVE ranging from 5.0 to $8.5 \%$ (Fig. 3). Three QTLs for stem rot resistance were identified at 12 DAI, namely q12DAI_S1B06.1 on B06 with 3.5 LOD and $8.4 \%$ PVE, $q 12 A I \_S 3 B 04.2$ on B04 with 3.6 LOD and 5.5\% PVE and q12DAI_S3B10.3 on B10 with 3.2 LOD and 6.3\% PVE. Two QTLs at 9 DAI were identified namely q9DAI_S1B08.1 on B08 (4.3 LOD and 7.0\% PVE), q9DAI_S3B10.2 on chromosome B10 (5.4 LOD and $8.5 \%$ PVE). Two QTLs at 6 DAI were identified namely q6DAI_S2B03.1 on B03 (4.2 LOD and 6.7\% PVE) and q6DAI_S3B04.2 on B04 (3.1 LOD and 5.0\% PVE). A QTL on chromosome B04 at $28 \mathrm{cM}$ found to be expressed at both infection stages, 6DAI and 12DAI.

\section{QTLs for plant architecture-related traits}

In total, 11 main-effect QTLs were identified for plant architecture-related traits such as root hairiness (HRN), leaf shape (LS), number of primary branches (NPB), number of secondary branches (NSB), plant height (PH), pod length (PL), shelling percentage (SP) and seed weight (SW) (Fig. 3).

Two main-effect QTLs, each on chromosome A01 ( $q H R N \_S 1 A 01.1$ with 3.3 LOD and 6.5\% PVE) and on chromosome B09 ( $q H R N \_S 1 B 09.3$ with LOD 6.0 and PVE $54.4 \%$ ), were identified for root hairiness, interestingly a common QTL on chromosome A06 for number of primary branches ( $q N P B \_S 2 A 06.1$ with LOD 3.6 and PVE $6.0 \%$ ) and number of secondary branches ( $q N S B \_S 2 A 06.1$ with LOD 3.3 and PVE 10.3\%). A single main-effect QTL was identified for leaf shape ( $q L S \_S 1 A 01.1$ with LOD 3.2 and PVE 4.9\%) on A01, for plant height ( $q$ PH_S1A10.1 with LOD 3.4 and PVE 6.5) on chromosome A10, for pod length ( $q P L \_S 1 B 07.1$ with LOD 4.2 and PVE $7.3 \%$ ) on chromosome B07 and for seed weight ( $q$ SWS1B09.1 with LOD 4.0 and PVE 6.6\%) on B09. Three QTLs were 


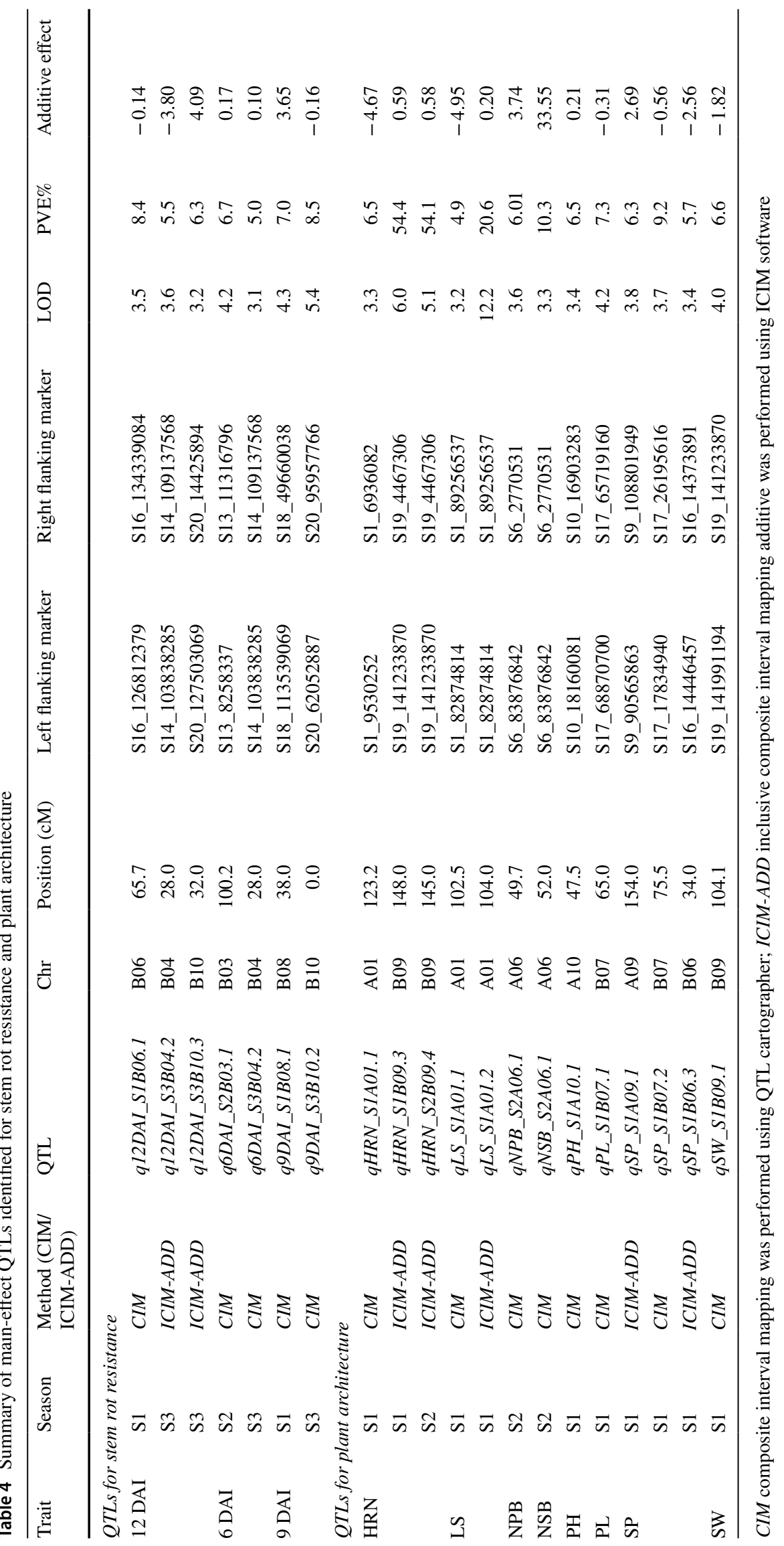




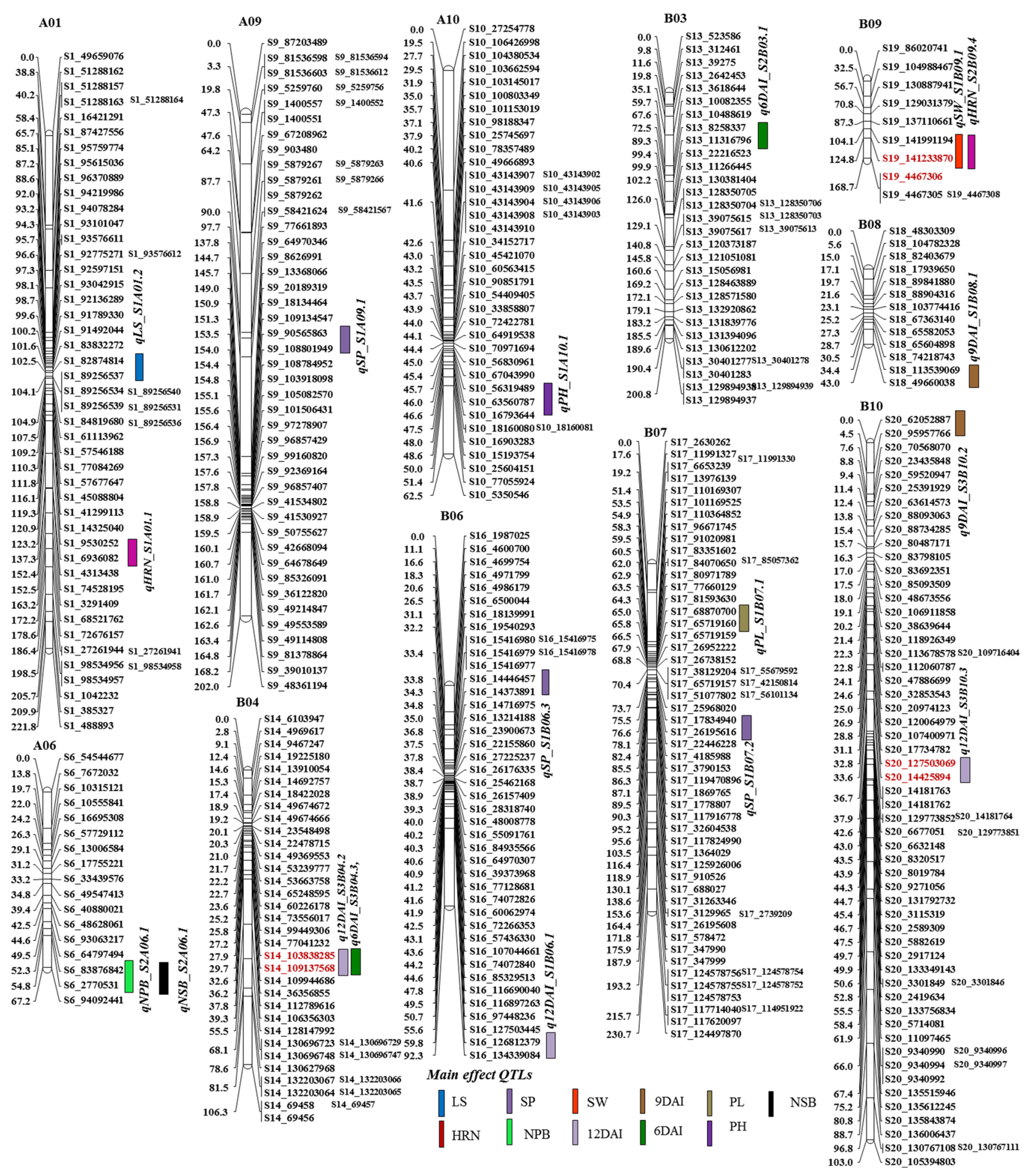

Fig. 3 Selected linkage groups (LGs) of dense genetic map of the RIL population showing main-effect QTLs associated with resistance to stem rot resistance and plant architecture

identified for shelling percentage namely $q S P \_S 1 A 09.1$ on A09 (LOD 3.8 and PVE 6.3\%), qSP_S1B07.2 on B07 (LOD 3.7 and PVE 9.2\%) and $q S P \_S 1 B 06.3$ on B06 (LOD 3.4 and PVE 5.7\%).

\section{Epistatic (QTL $\times$ QTL) QTLs for stem rot disease resistance}

Epistatic interaction $(Q \times Q)$ analysis identified a large 
number of epistatic QTLs (total 514) with the large range of PVE \% (5.8-59.0\%). Across three (S1, S2 and S3) seasons, 169 epistatic QTLs were identified for 12 DAI, 196 epistatic QTLs for 9 DAI and 149 epistatic QTLs for 6 DAI (Table 5, Fig. 4). Among epistatic QTLs, 8 consistent epistatic QTLs with high PVE were identified across the infection stages and seasons (Table 6). Three epistatic QTLs namely qtlA01.1 (PVE 43\%), qtlB01.1 (PVE 43\%) and qtlA03.1 (PVE 61\%) were identified in season S1 which interacts with various regions during resistance to stem rot disease. Similarly, two epistatic QTLs namely qtlB04.1 (PVE 46\%) and qtlA03.2 (PVE 61\%) were detected in S2 on chromosome B04 and A03, respectively. Three epistatic QTLs namely qtlA03.3 (PVE 55\%), qtlB01.2 (PVE 43.7\%) and qtlA09.1 (PVE 53.3\%) were mapped on chromosome A03, B01 and A09, respectively. The QTL on chromosome $\mathrm{A} 03$ expressed in two seasons ( $\mathrm{S} 1$ and $\mathrm{S} 3$ ).

\section{Discussion}

Stem rot resistance is very important for sustainability of groundnut production in stem rot affected areas of India and in other countries. This disease is most devastating and incurs huge yield loss including fodder. GAB can facilitate faster development of stem rot resistance varieties for timely replacement in farmers' field. However, no dedicated trait mapping and marker discovery study for stem rot resistance has been conducted so far in groundnut due to which currently GAB cannot be deployed. In this context, this comprehensive study has been conducted which resulted in availability of multi-season phenotyping data, high-quality genetic map, QTLs and linked markers for stem rot resistance. The information generated through this study also provides further opportunity for fine mapping, gene discovery and marker development for stem rot disease in groundnut.

\section{Stem rot disease: the most devastating disease in groundnut}

This disease has always been well known as the most devastating disease of the groundnut. The present experiment also confirms the same assumption and observed 50\%, 75\% and $100 \%$ loss of plant population at 6 DAI, 9 DAI and 12 DAI, respectively. The above results clearly indicated major crop damage (mostly yield and yield-related traits), highest at very advanced stage of the infection. Therefore, the advanced stage should be the perfect stage for phenotyping for conducting genetic mapping and also making reliable selection in the breeding programme for developing resistant varieties.

\section{Sequencing-based genotyping facilitated development of high-quality genetic map}

The large tetraploid genome (2.7 GB) of cultivated groundnut with narrow genetic base always posed challenge in achieving optimum genetic density. High marker density genetic maps are essential for conducting high-resolution genetic mapping and marker discovery. For example, the SSR-based genetic maps could achieve 135-191 mapped loci (Varshney et al. 2009; Ravi et al. 2011; Sujay et al. 2012; Gautami et al. 2012). Realizing this problem, high-density mapping has been achieved through sequencing technologies such as GBS, DArT/DArTseq and whole-genome resequencing (WGRS). The sequencing/SNP genotyping-based genetic maps were prepared with 1685 loci (Zhou et al. 2014) and DArT/DArTseq-based genetic maps with 854-1435 loci in $\mathrm{F}_{2}$ populations (Vishwakarma et al. 2016; Shasidhar et al. 2017). The present study reports development of highquality genetic map with 585 SNP loci with spanning the distance of $2430 \mathrm{cM}$ with an average inter-marker distance of $4.1 \mathrm{cM}$. Earlier, Bera et al. (2017) tried to develop SSRbased genetic map for conducting mapping for the same

Table 5 Summary of Epistatic QTLs detected in RIL population (TG37-A x NRCG CS85)

\begin{tabular}{|c|c|c|c|c|c|c|}
\hline S. No. & Trait name & $\begin{array}{l}\text { Total number of } \\
\text { epistatic }(Q \times Q) \text { inter- } \\
\text { actions }\end{array}$ & $\begin{array}{l}\text { Epistatic }(Q \times Q) \text { interactions } \\
\text { contributing towards suscepti- } \\
\text { bility }\end{array}$ & PVE range & $\begin{array}{l}\text { Epistatic }(Q \times Q) \text { interactions } \\
\text { contributing towards resistance }\end{array}$ & PVE $(\%)$ range \\
\hline 1 & 12DAI_S1 & 50 & 23 & $6.2-60.0$ & 27 & $4.8-61.7$ \\
\hline 2 & 12DAI_S2 & 56 & 27 & $5.2-20.6$ & 29 & $4.4-44.1$ \\
\hline 3 & 12DAI_S3 & 63 & 46 & $5.0-38.9$ & 17 & $4.5-41.3$ \\
\hline 4 & 9DAI_S1 & 54 & 29 & $6.0-59.1$ & 30 & $5.2-58.1$ \\
\hline 5 & 9DAI_S2 & 97 & 21 & $6.1-42.9$ & 26 & $5.5-32.4$ \\
\hline 6 & 9DAI_S3 & 45 & 38 & $6.8-61.5$ & 24 & $7.0-53.7$ \\
\hline 7 & 6DAI_S1 & 59 & 25 & $5.5-50.0$ & 29 & $5.0-44.0$ \\
\hline 8 & 6DAI_S2 & 47 & 37 & $5.6-59.5$ & 60 & $6.1-68.0$ \\
\hline 9 & 6DAI_S3 & 43 & 21 & $5.4-33.5$ & 24 & $6.2-46.0$ \\
\hline
\end{tabular}


(a)
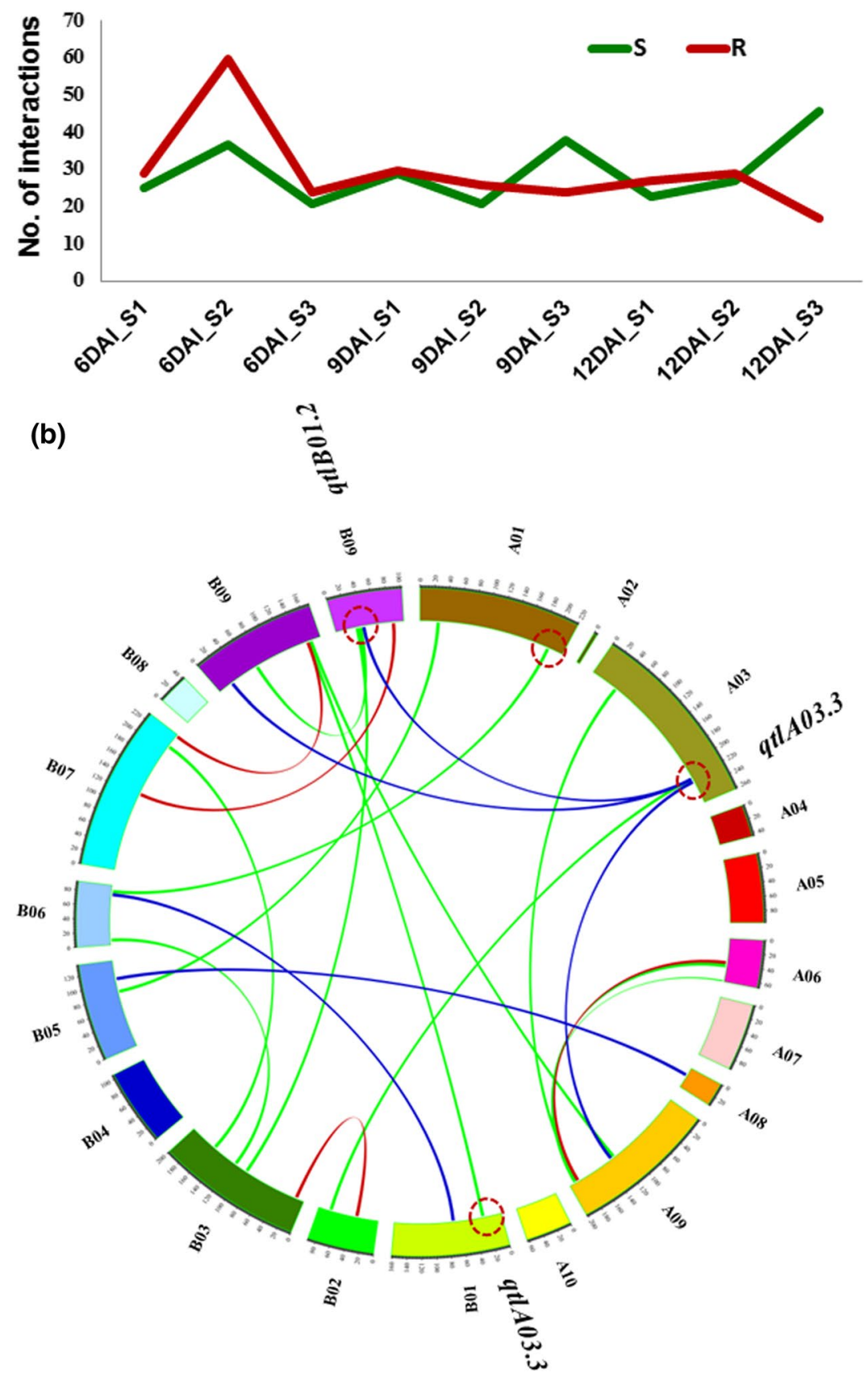

(c)

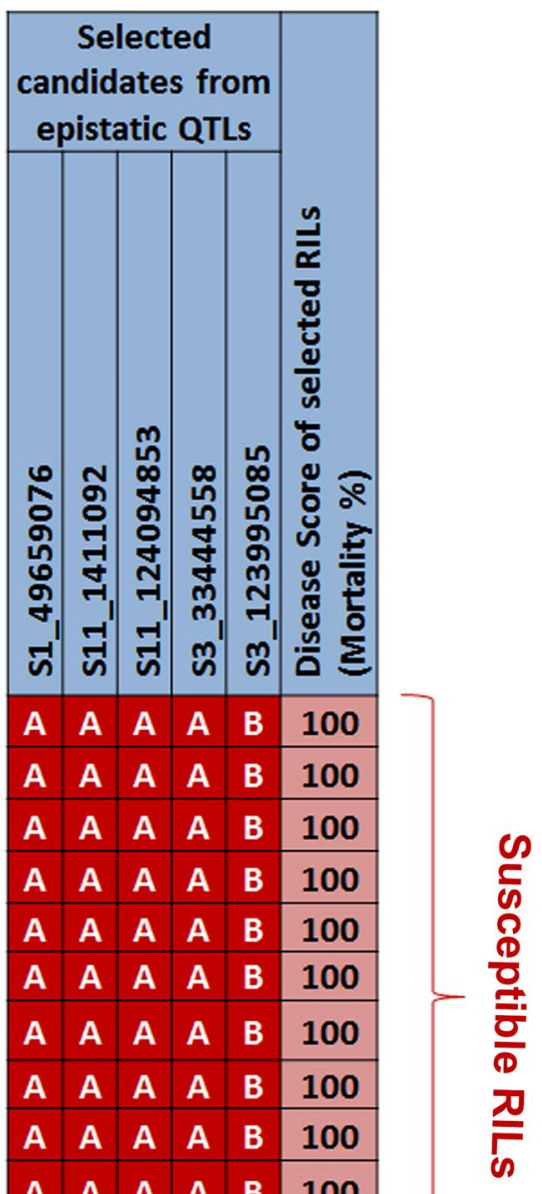

Fig. 4 Number of epistatic interactions contributing towards resistance and susceptibility against time of infection. a Major epistatic interactions (PVR\% $>30 \%$ ) for stem rot resistance; b Circos plot represents 20 linkage groups which are named as A01 to A10 and B01 to B10. Links inside the circle indicate the interactions between vari-

trait, however, could only identified 12 SSR polymorphic marker loci for stem rot disease resistance. Nevertheless, the availability of reference genomes of diploid progenitors ous genomic regions (epistatic loci) for stem rot resistance at different time of infections (12 DAI, 9 DAI and 6 DAI); c Selected five loci from the regions of epistatic QTLs showing association with the phenotype

(Bertioli et al. 2016; Chen et al. 2016) and now cultivated tetraploid genomes have enhanced the precision in SNP and candidate gene discovery in groundnut. 


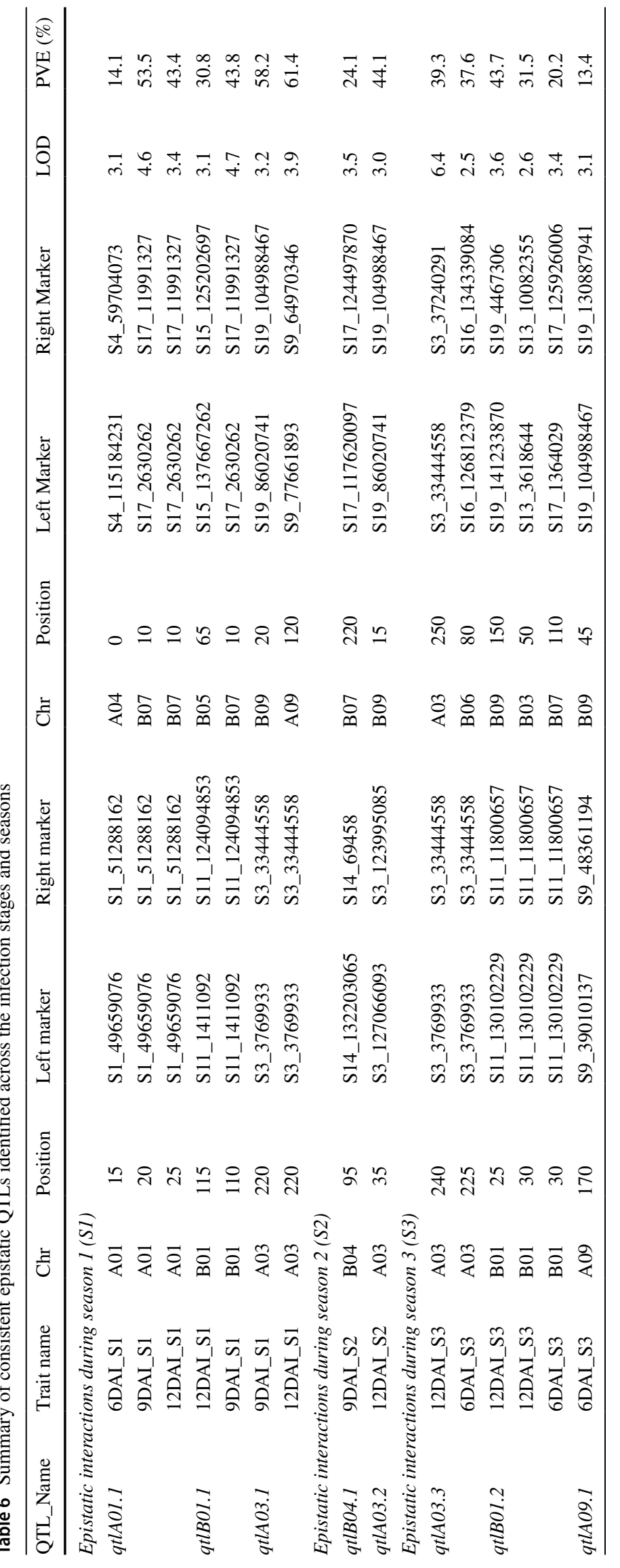




\section{Genetic dissection and QTL discovery analysis indicated complex genetic nature for stem rot resistance}

Use of two different genetic softwares showed difference in results where QTL cartographer showed relatively higher PVE than ICIM. A lone study conducted with just 12 mapped loci for stem rot resistance in groundnut reported one major QTL qstga01.1 with flanking markers GM2350 and TC4H02 (Bera et al. 2017). The high-quality SNP-based genetic map developed in present study allowed to conduct high-resolution genetic mapping leading to detection of 7 main-effect QTLs for stem rot resistance at different infection periods (6 DAI, 9 DAI, 12 DAI) with cumulative $47.4 \%$ PVE. This study clearly identified 'B' genome as the source of resistance which hosted all the 7 main-effect QTLs for stem rot resistance. The analysis also identified a potential genomic region for further investigation which harbours two main-effect QTLs for stem rot resistance.

In case of complex trait, the phenotype is a cumulative effect of few or many genes which is a barrier to recognize exact region controlling the effect of phenotype. The epistasis analysis conducted in present study identified large number of epistatic QTLs explaining PVE ranging from 4.4 to $68 \%$. It gives a clear understanding about genetic nature of stem rot disease which is a complex trait influenced by the cumulative effect of various genes across the genome. Similar results were also reported earlier for drought tolerance-related traits in groundnut (Ravi et al. 2011). In present study, the results showed an interesting trend among epistatic interactions against different time periods of infections. During the initial stage of infection (6 DAI), very few epistatic interactions were functioning in favour of susceptibility; in contrast, more interactions were contributed towards resistance. But, with increasing time after infection, the number of interactions was increased for susceptibility and decreased for resistance. This is may be due to the systemic acquired resistance (SAR) activated by (JA) and (SA) by activating effector triggered immunity (ETI) in response to infection of disease (Table 6).

\section{Candidate genes for stem rot resistance}

Based on the results obtained from QTL analysis, a genomic region of $5.2 \mathrm{Mb}$ was identified with two maineffect QTLs for stem rot disease resistance. This genomic region was identified on B04 with flanking markers (S14_103838285-S14_109137568 (Fig. 5). The 5.2-Mb QTL region on chromosome B04 (1.8 cM on genetic map) harbours two main-effect QTLs for stem rot resistance explains up to $\sim 11 \%$ PVE. Evaluation of this region with the peanut genome assembly followed by genome annotations identified a total of 170 genes (Table 7). This region is rich in NBS-LRR (nucleotide-binding site leucine-rich repeats), zinc finger motifs, ERF (ethylene-responsive factors), autophagy-related proteins and WRKY transcription

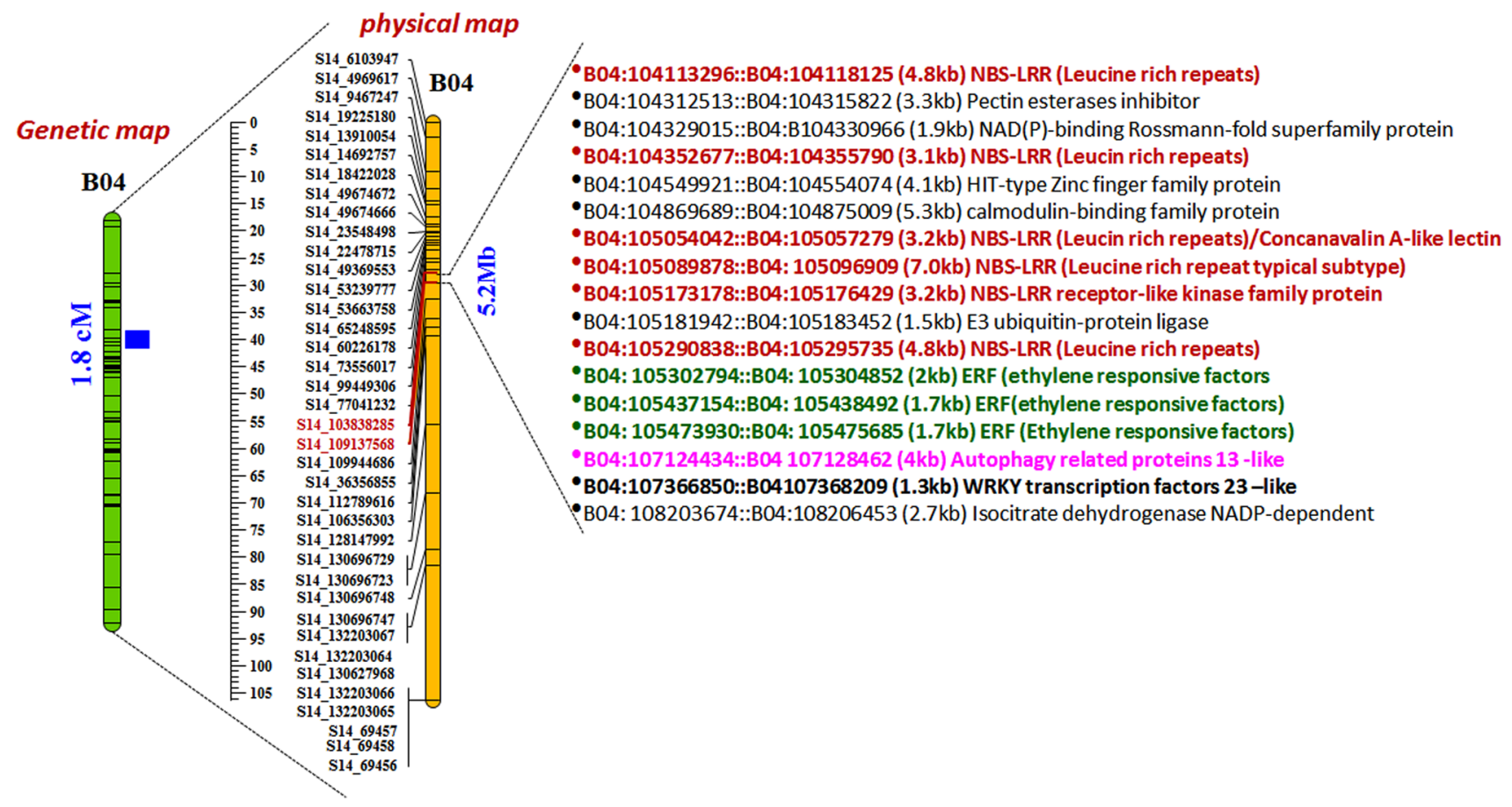

Fig. 5 Candidate genes identified in the 5.2 -Mb QTL region mapped on chromosome B04 
Table 7 Disease resistance genes identified in the 5.2-Mb QTL region and epistatic QTL regions

\begin{tabular}{|c|c|c|c|c|c|c|}
\hline $\mathrm{Chr}$ & Gene start & Gene end & $\begin{array}{l}\text { Length of } \\
\text { gene (bp) }\end{array}$ & Strand & Gene ID & Function \\
\hline \multicolumn{7}{|c|}{ Genes identified in the 5.2-Mb QTL region on chromosome B04 } \\
\hline Araip.B04 & 104113296 & 104118125 & 4830 & + & Araip.3TG36 & Leucine-rich repeat \\
\hline Araip.B04 & 104352677 & 104355790 & 3114 & + & Araip.13LX0 & Leucine-rich repeat \\
\hline Araip.B04 & 105054042 & 105057279 & 3238 & - & Araip.C6IN6 & Leucine-rich repeat \\
\hline Araip.B04 & 105089878 & 105096909 & 7032 & - & Araip.WMZ64 & Leucine-rich repeat \\
\hline Araip.B04 & 105173178 & 105176429 & 3252 & - & Araip.BZ3UW & LRR receptor-like kinase family Leucine-rich repeat \\
\hline Araip.B04 & 105290838 & 105295735 & 4898 & + & Araip.29WB6 & Leucine-rich repeat \\
\hline Araip.B04 & 106781989 & 106782734 & 746 & - & Araip.PP2EC & Leucine-rich repeat \\
\hline Araip.B04 & 104258699 & 104263382 & 4684 & - & Araip.46XVA & Ferritin (ferric iron binding) \\
\hline Araip.B04 & 104329015 & 104330966 & 1952 & + & Araip.LXM2D & NAD(P)-binding Rossmann-fold superfamily protein \\
\hline Araip.B04 & 104869689 & 104875009 & 5321 & + & Araip.GF9L5 & Calmodulin-binding family protein \\
\hline Araip.B04 & 105181942 & 105183452 & 1511 & - & Araip.XK459 & E3 ubiquitin-protein ligase \\
\hline Araip.B04 & 105302794 & 105304852 & 2059 & - & Araip.U663M & Ethylene-responsive transcription factor 7-like \\
\hline Araip.B04 & 105437154 & 105438492 & 1339 & - & Araip.LL89K & Ethylene-responsive transcription factor 7-like \\
\hline Araip.B04 & 105473930 & 105475685 & 1756 & - & Araip.I6HJK & Ethylene-responsive transcription factor 3-like \\
\hline Araip.B04 & 107124434 & 107128462 & 4029 & + & Araip.VE18D & Autophagy-related protein \\
\hline Araip.B04 & 107366850 & 107368209 & 1360 & - & Araip.XVA98 & Probable WRKY transcription factor \\
\hline Araip.B04 & 108203674 & 108206453 & 2780 & + & Araip.BZ4NA & Isocitrate dehydrogenase NADP dependent \\
\hline \multicolumn{7}{|c|}{ Genes identified in epistatic QTL regions } \\
\hline Aradu.A01 & 50259417 & 50262052 & 2635 & + & Aradu.99WG9 & Cytochrome P450 \\
\hline Aradu.A01 & 50802251 & 50806406 & 4155 & + & Aradu.0IN20 & Transducin/WD40 repeat-like \\
\hline Aradu.A01 & 50805913 & 50807517 & 1604 & - & Aradu.KJA6P & Riboflavin biosynthesis protein \\
\hline Aradu.A01 & 49977606 & 49981865 & 4259 & + & Aradu.U1MJX & Hydroxymethylglutaryl-CoA synthase like \\
\hline
\end{tabular}

factors. The majority of disease resistance genes in plants encode nucleotide-binding site leucine-rich repeat (NBSLRR) proteins (McHale et al. 2006) which is largest gene family encoded by hundreds of diverse genes per genome. Interestingly, we identified 6 isoforms of NBS-LRR proteins in 5.2-Mb region which might be key potential candidate genes for stem rot resistance. The programmable cell death (PCD) is regulated by the many defence proteins containing zinc finger domain. The Pi54 gene confers durable resistance to blast disease. Similarly, pI8 (sunflower), Pib (rice), LrlO (wheat), Grol-4 (potato), RCY1 (Arabidopsis) and Rpgl (barley) contain multiple number of zinc finger domains (Gupta et al. 2012). The ERF proteins involved in defence responses against pathogen infection have also been widely documented (Park et al. 2001; Shin et al. 2002; Gutterson and Reuber 2004), and overexpression of ERF genes in transgenic tobacco or Arabidopsis plants induces expression of several PR genes, resulting in enhanced resistance to various diseases caused by bacterial, fungal, viral pathogen (Zuo et al. 2007; Fischer and Dröge-Laser 2004).

WRKY transcription factors are functionally redundant and alter salicylic acid (SA) and jasmonic acid (JA) signalling in response to pathogen attack which modulates systemic defence response using effector triggered immunity
(ETI) (Durrant and Dong 2004). WRKY TFs also involve in modulating the expression of several miRNA during plant defence signalling (Pandey and Somssich 2009) (ESM 3, Fig. 5).

$\mathrm{R}$ genes along with NBS-LRR domain play a crucial role in regulating expression of the genes involved in plant resistance (Eulgem and Somssich 2007; Ulker and Somssich 2004). The blast resistance gene Pi54 contains NFX-type zinc finger domain in their protein. The NFX1-type zinc finger proteins are a group of the human $N F X 1$ transcription factors (Gupta et al. 2012). Overexpressing the GmERF3 gene in tobacco showed increased resistance to Ralstonia solanacearum, Alternaria alternata and TMV under normal environmental conditions (Zhang et al. 2009).

\section{Summary}

In summary, the study has successfully performed sequencing-based genotyping leading to a good- and high-quality genetic map for stem rot disease in groundnut. Using the multi-season phenotyping, data helped in dissecting the polymorphic nature of this important disease and facilitated identification of several genomic regions for stem rot 
resistance in groundnut. Most importantly, a 5.2-Mb QTL region on B04 comprising 170 genes was also discovered harbouring resistance genes such as LRR, ERF and zinc finger motifs. However, more investigation is required for further dissecting the 5.2-Mb region through fine mapping and assessing the potential of identified major-effect epistasis loci using next-generation sequencing technologies for causal resistance genes and genetic markers for use in breeding.

Author contribution statement SD, ALR, N, GPM and SC developed the RIL population, and JRD and SVC coordinated the experimental part of the project. AC performed sequencing of RIL population, and BJ and PPT phenotyped the RIL population. SSG, MKP and PS contributed to data analyses, SSG and MKP wrote the first manuscript, and RKV wrote the final version of the manuscript. RT initiated and coordinated the project. All authors reviewed the manuscript and provided suggestions.

Acknowledgments This project was supported by the National Agricultural Science Fund (NASF) of Indian Council of Agricultural Research (ICAR), New Delhi, India. The help rendered by Ms. Vanika Garg in sequence analysis is thankfully acknowledged. The sequencing work reported in this article was undertaken as a part of the CGIAR Research Program on Grain Legumes and Dryland Cereals (GLDC). ICRISAT is a member of the CGIAR.

\section{Compliance with ethical standards}

Conflict of interest The authors declare that there are no conflicts of interest.

Human or animal rights This study does not include human or animal subjects.

\section{References}

Akgul DS, Ozgonen H, Erkilic A (2011) The effects of seed treatments with fungicides on stem rot caused by Sclerotium rolfsii sacc., in peanut. Pak J Bot 43(6):2991-2996

Bera SK, Kumar V, Sunkad G, Rathnakumar AL, Radhakrisihnan T (2011) NRCGCS 85 (IC0582473; INGR10030), Groundnut (Arachis hypogaea) Germplasm, a source of Resistance to PBND (Peanut bud necrosis diseases), Stem Rot, Late Leaf Spot, Early Leaf Spot, Rust and Alternaria Leaf Blight. Indian J Plant Genet Resour 24(1):96-153

Bera SK, Kasundra SV, Kamdar JH, Ajay BC, Lal C, Thirumalasmy PP, Dash P, Maurya AK (2014) Variable response of interspecific breeding lines of groundnut to Sclerotium rolfsii infection under field and laboratory conditions. Electron J Plant Breed 5:22-29

Bera SK, Kamdar JH, Kasundra SV, Ajay BC (2017) A novel QTL governing resistance to stem rot disease caused by Sclerotium rolfsii in peanut. Australas Plant Pathol 45(6):637-644

Bertioli DJ, Cannon SB, Froenicke L, Huang G, Farmer AD, Cannon EK, Liu X, Gao D, Clevenger J, Dash S, Ren L, Moretzsohn
MC, Shirasawa K, Huang W, Vidigal B, Abernathy B, Chu Y, Niederhuth CE, Umale P, Araújo AC, Kozik A, Kim KD, Burow MD, Varshney RK, Wang X, Zhang X, Barkley N, Guimarães PM, Isobe S, Guo B, Liao B, Stalker HT, Schmitz RJ, Scheffler BE, Leal-Bertioli SC, Xun X, Jackson SA, Michelmore R, Ozias-Akins P (2016) The genome sequences of Arachis duranensis and Arachis ipaensis, the diploid ancestors of cultivated peanut. Nat Genet 48:438-446

Bradbury PJ, Zhang Z, Kroon DE, Casstevens TM, Ramdoss Y, Buckler ES (2007) TASSEL: software for association mapping of complex traits in diverse samples. Bioinformatics 23:2633-2635

Chen X, Li H, Pandey MK, Yang Q, Wang X, Garg V, Li H, Chi X, Doddamani D, Hong Y, Upadhyaya H, Guo H, Khan AW, Zhu F, Zhang X, Pan L, Pierce GJ, Zhou G, Krishnamohan KA, Chen M, Zhong N, Agarwal G, Li S, Chitikineni A, Zhang GQ, Sharma S, Chen N, Liu H, Janila P, Li S, Wang M, Wang T, Sun J, Li X, Li C, Wang M, Yu L, Wen S, Singh S, Yang Z, Zhao J, Zhang C, Yu Y, Bi J, Zhang X, Liu ZJ, Paterson AH, Wang S, Liang X, Varshney RK, Yu S (2016) Draft genome of the peanut A-genome progenitor (Arachis duranensis) provides insights into geocarpy, oil biosynthesis and allergens. Proc Natl Acad Sci USA 113:6785-6790

Cilliers AJ, Herselman L, Pretorius ZA (2000) Genetic variability within and among mycelial compatibility groups of Sclerotium rolfsii in South Africa. Phytopathology 90:1026-1031

Deepthi KC, Reddy NPE (2013) Stem rot disease of groundnut (Arachis hypogaea $\mathrm{L}$ ) induced by Sclerotium rolfsii and its management. Int J Life Sci Biotechnol Pharma Res 2(3):26-38

Durrant WE, Dong X (2004) Systemic acquired resistance. Annu Rev Plant Pathol 42:185-209

Elshire RJ, Glaubitz JC, Sun Q, Poland SA, Kawamoto K, Buckler ES, Mitchel SE (2011) A robust, simple genotyping-by-sequencing (GBS) approach for high diversity species. PLoS ONE 6:e19379

Eulgem T, Somssich IE (2007) Networks of WRKY transcription factors in defense signaling. Curr Opin Plant Biol 10:366-371

Fischer U, Dröge-Laser W (2004) Overexpression of NtERF5, a new member of the tobacco ethylene response transcription factor family enhances resistance to tobacco mosaic virus. Mol Plant Microbe Interact 17:1162-1171

Ganesan S, Kuppusamy GR, Sekar R (2007) Integrated management of stem rot disease (Sclerotium rolfsii) of groundnut (Arachis hypogaea L.) using rhizobium and Trichoderma harzianum (ITCC-4572). Turk J Agric For 31(2):103-108

Gautami B, Pandey MK, Vadez V, Nigam SN, Ratnakumar P, Krishnamurthy L, Radhakrishnan T, Gowda MVC, Narasu ML, Hoisington DA, Knapp SJ, Varshney RK (2012) Quantitative trait locus analysis and construction of consensus genetic map for drought tolerance traits based on three recombinant inbred line populations in cultivated groundnut (Arachis hypogaea L.). Mol Breeding 30:773-788

Gupta SK, Rai AK, Kanwar SS, Sharma TR (2012) Comparative analysis of zinc finger proteins involved in plant disease resistance. PLoS ONE 7(8):42578

Gutterson N, Reuber TL (2004) Regulation of disease resistance pathways by AP2/ERF transcription factors. Curr Opin Plant Biol 7:465-471

Kale DM, Murty GSS, Badigannavar AM (2004) TG 37A-a new Trombay groundnut variety with wide adaptation. Int Arachis Newsl 24:19-20

Li H, Durbin R (2009) Fast and accurate short read alignment with Burrows-Wheeler transform. Bioinformatics 25:1754-1760

McHale L, Tan X, Koehl P, Michelmore RW (2006) Plant NBS-LRR proteins: adaptable guards. Genome Biol 7(4):212

Meng L, Li H, Zhang L, Wang J (2015) QTL IciMapping: integrated software for genetic linkage map construction and quantitative trait locus mapping in biparental populations. Crop J 3:269-283 
Nigam SN, Rao MJ, Gibbons RW (1990) Artificial hybridization in groundnut. Information Bulletin No. 29. Patancheru, A.P. 502 324, India: International Crops Research Institute for the SemiArid Tropics

Pandey SP, Somssich IE (2009) The role of WRKY transcription factors in plant immunity. Plant Physiol 150:1648-1655

Pandey MK, Monyo E, Ozias-Akins P, Liang X, Guimarães P, Nigam SN, Upadhyaya HD, Janila P, Zhang X, Guo B, Cook DR, Bertioli DJ, Michelmore R, Varshney RK (2012) Advances in Arachis genomics for peanut improvement. Biotechnol Adv 30:639-651

Pandey MK, Roorkiwal M, Singh V, Lingam A, Kudapa H, Thudi M, Chitikineni A, Rathore A, Varshney RK (2016) Emerging genomic tools for legume breeding: current status and future perspectives. Front Plant Sci 7:45510

Pandey MK, Agarwal G, Kale SM, Clevenger J, Nayak SN, Sriswathi M, Chitikineni A, Chavarro C, Chen X, Upadhyaya HD, Vishwakarma MK, Bertoli SL, Liang X, Bertioli DJ, Guo B, Jackson SA, Ozias-Akins P, Varshney RK (2017) Development and evaluation of a high density genotyping 'Axiom_Arachis' array with $58 \mathrm{~K}$ SNPs for accelerating genetics and breeding in groundnut. Sci Rep 7:40577

Park JM, Park CJ, Lee SB, Ham BK, Shin R, Paek KH (2001) Overexpression of the tobacco Tsi1 gene encoding an EREBP/AP2-type transcription factor enhances resistance against pathogen attack and osmotic stress in tobacco. Plant Cell 13:1035-1046

Ravi K, Vadez V, Isobe S, Mir RR, Guo Y, Nigam SN, Gowda MV, Radhakrishnan T, Bertioli DJ, Knapp SJ, Varshney RK (2011) Identification of several small main-effect QTLs and a large number of epistatic QTLs for drought tolerance related traits in groundnut (Arachis hypogaea L.). Theor Appl Genet 122:1119-1132

Shasidhar Y, Vishwakarma MK, Pandey MK, Janila P, Variath MT, Manohar SS, Nigam SN, Guo B, Varshney RK (2017) Molecular mapping of oil content and fatty acids using dense genetic maps in groundnut (Arachis hypogaea L.). Front Plant Sci 8:794

Shin R, Park JM, Paek KH (2002) Ectopic expression of Tsil in transgenic hot pepper plants enhances host resistance to viral, bacterial, and oomycete pathogens. Mol Plant Microbe Interact 15:983-989

Shokes FM, Weber Z, Gorbet DW, Pudelko HA, Taczanowski M (1998) Evaluation of peanut genotypes for resistance to southern stem rot using an agar disk technique. Peanut Sci 25:12-17

Sujay V, Gowda MVC, Pandey MK, Bhat RS, Khedikar YP, Nadaf HL, Gautami B, Sarvamangala C, Lingaraju S, Radhakrishan T, Knapp SJ, Varshney RK (2012) Quantitative trait locus analysis and construction of consensus genetic map for foliar disease resistance based on two recombinant inbred line populations in cultivated groundnut (Arachis hypogaea L.). Mol Breed 30:773-788

Ulker B, Somssich IE (2004) WRKY transcription factors: from DNA binding towards biological function. Curr Opin Plant Biol 7:491-498

Van Ooijen JW (2006) JoinMap4, software for the calculation of genetic linkage maps in experimental populations. Kyazma BV, Wageningen, Netherland
Varshney RK, Bertioli DJ, Moretzsohn MC, Vadez V, Krishnamurty L, Aruna R, Nigam SN, Moss BJ, Seetha K, Ravi K, He G, Knapp SJ, Hoisington DA (2009) The first SSR based genetic linkage map for cultivated groundnut (Arachis hypogaea L.). Theor Appl Genet 118:729-739

Varshney RK, Mohan SM, Gaur PM, Gangarao NV, Pandey MK, Bohra A, Varshney RK, Mohan SM, Gaur PM, Gangarao NV, Pandey MK, Bohra A, Sawargaonkar SL, Chitikineni A, Kimurto PK, Janila P, Saxena KB, Fikre A, Sharma M, Rathore A, Pratap A, Tripathi S, Datta S, Chaturvedi SK, Mallikarjuna N, Anuradha G, Babbar A, Choudhary AK, Mhase MB, Bharadwaj Ch, Mannur DM, Harer PN, Guo B, Liang X, Nadarajan N, Gowda CL (2013) Achievements and prospects of genomics-assisted breeding in three legume crops of the semi-arid tropics. Biotechnol Adv 31:1120-1134

Varshney RK, Pandey MK, Janila P, Nigam SN, Sudini H, Gowda MVC, Sriswathi M, Radhakrishnan T, Manohar SS, Nagesh P (2014) Marker-assisted introgression of a QTL region to improve rust resistance in three elite and popular varieties of peanut (Arachis hypogaea L.). Theor Appl Genet 127(8):1771-1781

Vishwakarma MK, Pandey MK, Shasidhar Y, Manohara SS, Nagesh P, Janila P (2016) Identification of two major quantitative trait locus for fresh seed dormancy using the diversity arrays technology and diversity arrays technology-seq based genetic map in Spanish-type peanuts. Plant Breed 135:367-375

Vishwakarma MK, Kale SM, Sriswathi M, Naresh T, Shasidhar Y, Garg V, Pandey MK, Varshney RK (2017) Genome-wide discovery and deployment of insertions and deletions markers provided greater insights on species, genomes, and sections relationships in the genus Arachis. Front Plant Sci 8:2064

Voorrips RE (2002) Mapchart: software for the graphical presentation of linkage maps and QTLs. J Hered 93:77-78

Wang SC, Bastern J, Zeng ZB (2011) Windows QTL Cartographer 2.5. Department of Statistics, North Carolina State University, Raleigh

Wang J, Li H, Zhang L, Meng L (2012) Users' manual of QTL IciMapping version 3.3. Chinese Academy of Agricultural Sciences (CAAS), Beijing

Zhang G, Chen M, Li L, Xu Z, Chen X, Gou J, Ma Y (2009) Over expression of soya bean GmERF3 gene, an AP2/ERF type transcription factor for increased tolerance to salt drought and disease in transgenic tobacco. J Exp Bot 60(13):3781-3796

Zhou X, Xia Y, Ren X, Chen Y, Huang L, Huang S, Liao B, Lei Y, Yan L, Jiang H (2014) Construction of an SNP-based genetic linkage map in cultivated peanut based on large-scale marker development using next-generation double-digest restriction-site-associated DNA sequencing (ddRADseq). BMC Genom 15:351

Zuo KJ, Qin J, Zhao JY, Ling H, Zhang LD, Cao YF, Tang KX (2007) Over-expression GbERF2 transcription factor in tobacco enhances brown spots disease resistance by activating expression of downstream genes. Gene 391:80-90 